\title{
Pengembangan Media Pembelajaran Booklet Penyuluhan tentang Pembuatan Nata de Melon bagi Masyarakat Petani
}

\author{
Yossie Ulfa Nuzalifa ${ }^{1}$, Utami Sri Hastuti ${ }^{1}$, Sueb $^{1}$ \\ ${ }^{1}$ Pendidikan Biologi-Universitas Negeri Malang
}

\begin{tabular}{l}
\hline \hline INFO ARTIKEL \\
\hline Riwayat Artikel: \\
Diterima: $31-05-2018$ \\
Disetujui: $14-03-2019$ \\
\hline
\end{tabular}

\section{Kata kunci:}

booklet; nata de melon; melon farmers; booklet; nata de melon; masyarakat petani melon

\author{
Alamat Korespondensi: \\ Yossie Ulfa Nuzalifa \\ Pendidikan Biologi \\ Universitas Negeri Malang \\ Jalan Semarang 5 Malang \\ E-mail: yossieulfa1811@gmail.com
}

\begin{abstract}
ABSTRAK
Abstract: Booklet is one of the learning media developed to complement the implementation of non-formal education, especially for extension activities for farmers. The purpose of this development research is to produce a booklet extension about Nata de Melon. The development model used the Hannafin \& Peck development model. The booklet is validated by material expert validator, media expert validator and fruit farmers as respondents for legibility test. Data collection techniques is done through questionnaires and analyzed by qualitative and quantitave. The results showed that validation scores booklet by material expert were $94.40 \%$, media expert $98.26 \%$ and readability tests conducted with 10 respondents showed a score of $95.33 \%$. Overall the resulting score shows that the validity criteria is very valid, so the booklet extension about Nata de Melon is suitable to be a learning materials media for the fruit farmers.

Abstrak: Booklet merupakan salah satu media pembelajaran yang dikembangkan untuk melengkapi pelaksanaan pendidikan non-formal, khususnya untuk kegiatan penyuluhan bagi petani. Tujuan penelitian pengembangan ini yaitu untuk menghasilkan booklet penyuluhan tentang Nata de Melon. Model pengembangan yang digunakan yaitu model pengembangan Hannafin \& Peck. Booklet divalidasi oleh validator ahli materi, validator ahli media dan masyarakat petani sebagai responden uji keterbacaan. Teknik pengumpulan data melalui angket dan dianalisis secara kualitatif dan kuantitatif. Hasil penelitian menunjukkan skor validasi booklet oleh ahli materi yaitu 94,40\%, ahli media $98,26 \%$ dan uji keterbacaan yang dilakukan dengan 10 responden menunjukkan skor 95,33\%. Secara keseluruhan, skor yang dihasilkan menunjukkan bahwa kriteria kevalidan booklet termasuk pada kriteria sangat valid sehingga booklet penyuluhan Nata de Melon dinyatakan layak digunakan sebagai media pembelajaran bagi masyarakat petani buah.
\end{abstract}

Pendidikan memiliki peranan penting dalam menumbuhkan kualitas hidup yang lebih baik bagi seseorang. Jalur pendidikan dapat ditempuh melalui pendidikan formal di sekolah dan pendidikan nonformal di luar sekolah. Pendidikan nonformal merupakan jalur pendidikan di luar sekolah yang dapat dilaksanakan secara terstruktur dan berjenjang (UU Nomor 20 Tahun 2003). Pada umumnya pendidikan nonformal diperuntukkan bagi masyarakat yang memiliki kendala dalam melanjutkan pendidikan formal. Kendala yang umum dialami, yaitu tidak memiliki biaya yang cukup untuk melanjutkan pendidikan formal ke jenjang yang lebih tinggi sehingga mengikuti kegiatan pendidikan nonformal merupakan salah satu alternatif yang dapat ditempuh.

Pendidikan nonformal saat ini sudah banyak dikenal oleh masyarakat Indonesia sebagai pendidikan pengganti, pelengkap ataupun sebagai pendidikan tambahan di samping pendidikan formal. Salah satu bentuk pendidikan nonformal yaitu pendidikan keterampilan dan pelatihan kerja yang terintegrasi dengan kegiatan penyuluhan untuk masyarakat. Penyuluhan dapat didefenisikan sebagai suatu kegiatan yang melibatkan seseorang dan kelompok masyarakat untuk menyampaikan dan menerima informasi secara sadar yang bertujuan untuk membantu sesama sehingga dapat membuat keputusan yang benar. Kegiatan penyuluhan juga merupakan salah satu landasan pendidikan bagi masyarakat dalam mengurangi kemiskinan dan meningkatkan kemampuan serta keterampilan diri mereka melalui pembelajaran langsung (Gombe et al., 2016). Dengan demikian, mereka yang tidak berkesempatan melanjutkan studi atau putus sekolah karena berbagai alasan, dapat diberikan kesempatan untuk mengembangkan kemampuan dan pengetahuan agar kehidupan mereka lebih sejahtera melalui pendidikan non formal.

Budidaya melon saat ini mengalami peningkatan yang cukup pesat, bahkan untuk kepentingan komersial banyak petani yang membudidayakan varietas melon manis dengan kadar gula tinggi, berukuran besar dan beraroma (Kaleka, 2015). Produksi melon di Indonesia yang cukup tinggi yaitu di Provinsi Jawa Timur, khususnya di Kabupaten Banyuwangi. Menurut data Dinas 
Pertanian dan Ketahanan Pangan Jawa Timur (2015), tujuan pasar pada pemasaran buah melon di kabupaten Banyuwangi ini terbagi atas empat pasar, yaitu 5\% ke pasar lokal, 25\% ke pasar luar kabupaten, 40\% pasar provinsi, dan 30\% pasar internasional. Meskipun pemasaran melon hingga ke luar negeri, para petani melon mendapat keuntungan yang rendah dan kurang sesuai dengan biaya produksi. Hal ini disebabkan karena para petani hanya menjual melon berupa buah segar. Ketika panen raya tak jarang para petani mengalami kerugian karena daya tahan simpan melon yang singkat. Buah melon yang mengalami kerusakan dan penurunan kualitas tidak dapat dipasarkan. Oleh karena itu, untuk mengatasi permasalahan tersebut para petani biasanya akan menjadikan buah melon sebagai bahan olahan untuk minuman jus.

Salah satu inovasi lain yang dapat dilakukan oleh masyarakat petani buah ketika panen raya terjadi yaitu dengan memanfaatkan melon menjadi minuman fermentasi berupa nata dari buah melon. Berdasarkan hasil analisis kebutuhan yang disebarkan kepada 15 orang responden diketahui hanya sebanyak $40 \%$ responden menyatakan sudah mengetahui bahwa melon dapat dijadikan bahan olahan berupa Nata de Melon. Namun demikian, meskipun mereka menyatakan sudah mengetahui pemanfaatan buah melon dalam bentuk nata, namun secara keseluruhan responden menyatakan bahwa perlu diadakan kegiatan pelatihan dalam pembuatan olahan buah melon menjadi Nata de Melon.

Kegiatan penyuluhan dan pelatihan yang diadakan diharapkan dapat membantu pemahaman yang lebih baik lagi pada para responden dalam proses pengolahannya. Proses pembuatan Nata de Melon memiliki beberapa tahapan yang terstruktur dan memerlukan beberapa alat serta bahan yang sesuai kebutuhan. Kegiatan pelatihan dan penyuluhan kepada masyarakat petani memerlukan media pembelajaran berupa booklet. Booklet adalah salah satu bahan ajar cetak berupa buku berukuran relatif kecil yang memuat informasi dan pengetahuan praktis tentang suatu subjek ataupun bidang ilmu tertentu (Pribadi, 2017).

Keunggulan booklet sebagai media bahan ajar yaitu memiliki tampilan desain dan gambar yang menarik, dilengkapi dengan gambar serta informasi yang ditulis secara sistematis agar mudah dipahami sehingga dapat membantu dan memfasilitasi pembaca sesuai dengan kebutuhan yang diperlukan (Bolejko et al., 2008). Gambar yang menarik serta langkah kerja yang ditulis secara sistematis pada booklet dapat membantu para petani untuk lebih mudah memahami isi booklet. Booklet yang dikemas sesuai dengan sasaran pembaca akan menjadikan media pembelajaran tersebut lebih bermakna (Citrawathi et al., 2009) dan pesan yang disampaikan dalam booklet dapat menumbuhkan motivasi diri pembaca dalam mengikuti proses pembelajaran (Oliveira et al., 2014). Hal ini berkaitan dengan tingkat pendidikan formal para petani yang bervariasi dan umumnya hanya lulusan Sekolah Menengah Pertama sehingga mereka memerlukan penjelasan lebih sederhana dan motivasi dalam belajar.

\section{METODE}

Penelitian ini merupakan penelitian pengembangan yang menggunakan model Hannafin \& Peck. Model pengembangan ini terdiri dari tiga tahapan yaitu, tahap analisis kebutuhan, tahap desain dan terakhir adalah tahap pengembangan dan implementasi. Pada penelitian ini tahapan dari model pengembangan Hannafin \& Peck yang diikuti dibatasi sampai pada tahap pengembangan yaitu uji keterbacaan yang dilakukan oleh masyarakat petani sebagai responden. Booklet divalidasi oleh validator ahli media dan ahli materi, serta 10 orang petani buah di kabupaten Banyuwangi desa Kedungsumur sebagai responden untuk menguji keterbacaan produk booklet. Data yang dikumpulkan berupa data kualitatif dan kuantitatif yang diperoleh dari hasil validasi ahli materi, validasi ahli media dan hasil uji keterbacaan produk booklet. Data kualitatif yang meliputi saran dan pendapat dianalisis dengan cara membaca kembali keseluruhan saran dan komentar, kemudian ditarik simpulan dan disampaikan secara deskriptif (Raco, 2013). Data kuantitatif dianalisis dengan menggunakan rumus perhitungan sebagai berikut.

$$
V-a h=\frac{T s e}{T s h} \times 100 \%
$$

Keterangan:

$V$-ah: validitas ahli

Tse : total skor empiris validator

Tsh : skor maksimal yang diharapkan

(Sumber: Akbar, 2013)

Kriteria kevalidan dan keterbacaan produk dapat dilihat pada tabel 1. Booklet dikatakan valid apabila tingkat kevalidan termasuk pada kriteria sangat valid dan valid. Apabila termasuk pada kriteria cukup valid, kurang valid, dan tidak valid maka booklet tidak dapat digunakan.

Tabel 1. Kriteria Kevalidan dan Keterbacaan Produk

\begin{tabular}{cl}
\hline Kriteria Nilai & \multicolumn{1}{c}{ Tingkat Validitas } \\
\hline $85,01-100 \%$ & Sangat valid; dapat digunakan dengan sedikit perbaikan \\
\hline $70,01-85,00 \%$ & Cukup valid; dapat digunakan namun perlu perbaikan kecil \\
\hline $50,01-70,00 \%$ & Kurang valid; disarankan tidak digunakan karena perlu revisi besar \\
\hline $01,01-50,00 \%$ & Tidak valid; tidak boleh digunakan \\
\hline
\end{tabular}




\section{HASIL}

Booklet penyuluhan sebagai media bahan ajar disusun berdasarkan kebutuhan informasi yang diperlukan masyarakat petani melon desa Kedungsumur dalam memanfaatkan melon sebagai produk olahan pangan berupa Nata de Melon. Booklet terdiri dari tiga bagian utama yaitu materi pendahuluan, materi utama dan materi pendukung. Melalui booklet penyuluhan diharapkan agar masyarakat petani buah dapat termotivasi untuk lebih memanfaatkan keadaan buah ketika panen raya tiba.

Hasil analisis kebutuhan menunjukkan bahwa hanya sebagian kecil petani mengetahui bahwa buah melon dapat diolah menjadi Nata. Berdasarkan hal tersebut, maka materi pendahuluan diisi dengan topik (1) Mengenal Nata de Coco dan Manfaatnya, (2) Biologi Tanaman Melon, (3) Prospek Pemanfaatan Melon untuk Bahan Dasar Nata de Melon, dan (4) Penilaian Kualitas Nata. Hasil analisis kebutuhan juga menunjukkan bahwa masyarakat petani belum pernah membuat Nata dari buah melon dan belum mengetahui tentang cara pembuatannya. Berdasarkan hal tersebut maka bagian materi utama booklet diisi dengan topi, yaitu (1) Alat dan Bahan untuk Pembuatan Nata de Melon, (2) Langkah Kerja Pembuatan Nata de Melon, dan (3) Pengolahan Nata de Melon. Booklet ini telah melalui beberapa tahapan validasi guna mengetahui tingkat kevalidan dan keterbacaannya. Tahapan validasi yang dilakukan oleh validator ahli media, ahli materi, dan validator pengguna yaitu masyarakat petani bertujuan untuk menilai kelayakan booklet agar layak digunakan sebagai media pembelajaran.

\section{Validasi Ahli Materi}

Data hasil validasi booklet oleh ahli materi menunjukkan kategori validitas sangat valid sehingga dapat digunakan dengan sedikit perbaikan. Data hasil validasi ahli materi dapat dilihat pada tabel 2.

Tabel 2. Hasil Validasi Booklet oleh Ahli Materi

\begin{tabular}{cccc}
\hline No & Aspek Penilaian & Persentase (\%) & Kategori \\
\hline 1. & Desain Booklet & 91,67 & Sangat Valid; dapat digunakan dengan sedikit perbaikan \\
2. & Bagian I & 95 & Sangat Valid; dapat digunakan dengan sedikit perbaikan \\
3. & Bagian II & 97,22 & Sangat Valid; dapat digunakan dengan sedikit perbaikan \\
4. & Bagian III & 93,75 & Sangat Valid; dapat digunakan dengan sedikit perbaikan \\
& Rerata (\%) & $\mathbf{9 4 , 4 0}$ & Sangat Valid; dapat digunakan dengan sedikit perbaikan \\
\hline
\end{tabular}

Berdasarkan tabel 2, tingkat kevalidan booklet menurut ahli materi termasuk pada kategori sangat valid dengan perolehan rerata sebesar $94,40 \%$. Adapun keterangan tambahan pada kategori sangat valid yaitu dapat digunakan dengan sedikit perbaikan berdasarkan saran dan pendapat yang diberikan oleh ahli materi sehingga layak digunakan sebagai bahan ajar penyuluhan pada masyarakat petani. Saran dan masukan yang disampaikan untuk menyempurnakan materi isi booklet antara lain (1) penambahan penjelasan komponen nutrisi melon, (2) mengurangi materi yang tidak begitu berkaitan, namun menonjol pada bagian materi pendahuluan sehingga menyebabkan uraian kurang jelas, dan (3) perbaikan kata yang salah ketik.

\section{Validasi Ahli Media}

Data hasil validasi booklet oleh ahli media menunjukkan kategori validitas sangat valid sehingga dapat digunakan dengan sedikit perbaikan. Data hasil validasi ahli media dapat dilihat pada tabel 3.

Tabel 3. Hasil Validasi Booklet oleh Ahli Media

\begin{tabular}{clcc}
\hline No & Aspek Penilaian & Persentase (\%) & Kategori \\
\hline 1. & Desain Sampul Booklet & 95,83 & Sangat Valid; dapat digunakan dengan sedikit perbaikan \\
2. & Aspek Bahasa & 100 & Sangat Valid; dapat digunakan dengan sedikit perbaikan \\
3. & Desain Isi Booklet & 97,22 & Sangat Valid; dapat digunakan dengan sedikit perbaikan \\
4. & Materi Penunjang & 100 & Sangat Valid; dapat digunakan dengan sedikit perbaikan \\
& Rerata (\%) & $\mathbf{9 8 , 2 6}$ & Sangat Valid; dapat digunakan dengan sedikit perbaikan \\
\hline
\end{tabular}

Berdasarkan tabel 3, tingkat kevalidan booklet menurut ahli media termasuk pada kategori sangat valid dengan perolehan rerata sebesar 98,26\%. Adapun keterangan tambahan, yaitu booklet dapat digunakan dengan sedikit perbaikan berdasarkan saran dan pendapat yang diberikan oleh ahli media pembelajaran, sehingga layak digunakan sebagai bahan ajar penyuluhan pada masyarakat petani. Saran dan pendapat yang disampaikan untuk menyempurnakan booklet dari segi kemenarikan dan kepraktisan, antara lain (1) booklet dicetak dengan menggunakan jilid ring sehingga memudahkan masyarakat petani dalam membuka lembar isi booklet, (2) penulisan nomor pada halaman sebaiknya dibuat sesuai aturan pembuatan buku, dan (3) ditinjau dari segi grafis dan gradasi warna, booklet yang disusun sudah menarik perhatian pembaca untuk dipelajari.

\section{Uji Keterbacaan oleh Responden}

Data hasil uji keterbacaan booklet oleh masyarakat petani sebagai responden menunjukkan kategori kevalidan sangat valid sehingga dapat digunakan dengan sedikit perbaikan. Data hasil uji keterbacaan oleh responden dapat dilihat pada tabel 4. 
Tabel 4. Hasil Uji Keterbacaan Booklet Responden

\begin{tabular}{cccccc}
\hline No & Responden & $\begin{array}{c}\text { Skor } \\
\text { Maksimal }\end{array}$ & $\begin{array}{c}\text { Skor } \\
\text { Validasi }\end{array}$ & Persentase (\%) & Kategori \\
\hline 1. & R1 & 60 & 60 & 100 & Sangat Valid; dapat digunakan dengan sedikit perbaikan \\
2. & R2 & 60 & 56 & 93,33 & Sangat Valid; dapat digunakan dengan sedikit perbaikan \\
3. & R3 & 60 & 57 & 95 & Sangat Valid; dapat digunakan dengan sedikit perbaikan \\
4. & R4 & 60 & 58 & 96,67 & Sangat Valid; dapat digunakan dengan sedikit perbaikan \\
5. & R5 & 60 & 60 & 100 & Sangat Valid; dapat digunakan dengan sedikit perbaikan \\
6. & R6 & 60 & 55 & 91,67 & Sangat Valid; dapat digunakan dengan sedikit perbaikan \\
7. & R7 & 60 & 54 & 90 & Sangat Valid; dapat digunakan dengan sedikit perbaikan \\
8. & R8 & 60 & 54 & 90 & Sangat Valid; dapat digunakan dengan sedikit perbaikan \\
9 & R9 & 60 & 60 & 100 & Sangat Valid; dapat digunakan dengan sedikit perbaikan \\
10. & R10 & 60 & 58 & 96,67 & Sangat Valid; dapat digunakan dengan sedikit perbaikan \\
& & Rerata (\%) & & $\mathbf{9 5 , 3 3}$ & Sangat Valid; dapat digunakan dengan sedikit perbaikan \\
\hline
\end{tabular}

Tabel 4 menunjukkan bahwa rerata hasil uji keterbacaan booklet yang dilakukan oleh 10 orang masyarakat petani buah sebagai responden menghasilkan skor sebesar 95,33\%. Hal ini menunjukkan bahwa booklet yang sudah disusun dan dikembangkan sebagai media bahan ajar termasuk dalam kategori sangat valid sehingga layak digunakan sebagai media bahan ajar untuk materi penyuluhan pembuatan Nata de Melon. Booklet juga layak digunakan dengan sedikit perbaikan karena sudah menunjukkan tampilan yang menarik dan materi yang disajikan mudah dipahami. Adapun saran dan pendapat yang disampaikan oleh para responden, antara lain (1) tampilan booklet bagus, menarik, dan mudah dibaca, (2) informasi yang disampaikan di dalam buku dapat menambah pengetahuan, dan (3) gambar yang ada di buku menarik dan disertai keterangan yang jelas.

\section{PEMBAHASAN}

Masyarakat di Kabupaten Banyuwangi Desa Kedungsumur sebagian besar memiliki tingkat pendidikan formal yang rendah sehingga memengaruhi kemampuan mereka dalam memperoleh pengetahuan dan mengembangkan diri menjadi lebih baik terhadap hasil panen melon yang dimiliki. Kegiatan pelatihan dan penyuluhan merupakan salah satu jenis pendidikan nonformal yang dapat dilakukan di masyarakat dengan tujuan agar masyarakat petani memperoleh pengetahuan yang lebih baik. Hasil penelitian El-Sayd \& Soha (2014) menyatakan bahwa melalui kegiatan penyuluhan, petani mendapatkan informasi yang dapat membantu dalam memperbaiki dan meningkatkan hasil pertanian mereka. Hal ini juga diperkuat dengan Undang-undang Nomor 16 Tahun 2006 tentang Sistem Penyuluhan Pertanian, Perikanan, dan Kehutanan yang menyatakan bahwa penyuluhan adalah suatu proses pembelajaran bagi pelaku utama dan pelaku usaha agar mereka mampu mengorganisasikan dirinya dalam mengakses informasi pasar, teknologi, permodalan, dan sumber daya lainnya sebagai upaya untuk meningkatkan produktivitas, efisiensi usaha, pendapatan dan kesejahteraan serta meningkatkan kesadaran dalam pelestarian fungsi lingkungan hidup.

Kegiatan penyuluhan memerlukan media bahan ajar yang sesuai dengan kebutuhan petani berupa booklet. Booklet dipilih karena diketahui efektif dalam meningkatkan pengetahuan (Eschalier et al., 2013) karena dengan membaca booklet seseorang mendapatkan lebih banyak informasi yang bermanfaat (Guillot \& Keenan, 2016) dan lebih mudah memahami informasi yang disampaikan dibandingkan dengan penyampaian secara lisan (Al-Muhdar et al., 2018). Penggunaan booklet dalam kegiatan pembelajaran juga dapat meningkatkan kualitas belajar dan adanya pengaruh yang positif terhadap prestasi belajar responden (Sulaiman et al., 2018; Sachriani et al., 2019). Kelebihan lain pada booklet yaitu dapat dengan mudah digunakan oleh siapa saja dan ringan untuk dibawa kemana saja, seperti misalnya di rumah, di sekolah, di rumah sakit, di perkebunan, dan di tempat lainnya (Pereira et al., 2012). Kemudahan yang terkandung dalam isi materi dan pesan yang ada pada booklet menjadikannya pilihan terbaik untuk responden ataupun pembaca dari semua kalangan dan keadaan.

Isi materi booklet yang berjudul "Nata de Melon, Minuman Kesehatan yang Kaya Serat Alami" dikembangkan berdasarkan hasil penelitian eksperimen tentang: Pengaruh Variasi Varietas dan Macam Gula terhadap Kualitas Nata de Melon, sehingga booklet bersifat kontekstual. Hasil penelitian tersebut menunjukkan bahwa melon varietas Indorif dengan penambahan gula pasir memberikan hasil lapisan nata yang terbaik. Sebagian besar hasil penelitian eksperimen tersebut digunakan sebagai materi utama dalam penyusunan isi booklet, khususnya pada bagian langkah kerja. Ilustrasi gambar digunakan dalam penjelasan tentang alat, bahan dan langkah kerja pembuatan nata serta teknik pengemasan sebagai materi pendukung dengan tujuan agar masyarakat petani melon di desa Kedungsumur Kabupaten Banyuwangi dapat dengan mudah memahami dan mengerjakannya secara mandiri. Hal tersebut juga didukung oleh pendapat Sungkono (2009) yang menyatakan bahwa uraian materi yang ada pada bahan ajar seharusnya disajikan secara naratif atau pikrotial yang bertujuan agar dapat merangsang dan mengondisikan tumbuhnya pengalaman belajar (learning experiences) seseorang. 
Booklet penyuluhan pembuatan Nata de Melon yang dikembangkan telah divalidasi oleh validator ahli materi, validator ahli media dan diuji keterbacaannya oleh 10 orang masyarakat petani sebagai responden. Booklet juga telah melalui tahap revisi sesuai dengan saran dan pendapat dari para validator dan masyarakat petani di desa Kedungsumur. Berdasarkan tahapan tersebut, tingkat kevalidan booklet termasuk pada kategori sangat valid sehingga booklet penyuluhan Nata de Melon layak digunakan sebagai media pembelajaran dalam kegiatan penyuluhan yang dapat memberikan informasi dan pengetahuan pada pembaca terutama para petani buah.

\section{SIMPULAN}

Booklet penyuluhan pembuatan Nata de Melon yang dikembangkan berbasis penelitian eksperimen menunjukkan kategori sangat valid sehingga layak digunakan dengan sedikit perbaikan sesuai dengan saran dan pendapat dari para validator. Responden yang memberikan penialaian berdasarkan uji keterbacaan menyatakan bahwa booklet sudah menarik dan informasi yang disampaikan bermanfaat bagi mereka. Berdasarkan hal tersebut dapat disimpulkan bahwa booklet dapat digunakan sebagai media pembelajaran dalam pelaksanaan pendidikan nonformal yang terintegrasi pada kegiatan penyuluhan dan pelatihan.

Peneliti selanjutnya agar mempertimbangkan untuk melakukan uji keefektifan terhadap booklet penyuluhan tentang pembuatan Nata de Melon ini kepada petani buah sehingga booklet dapat dinilai dari segi pengetahuan ataupun keterampilan guna mengetahui keefektifan bahan ajar yang dikembangkan.

\section{DAFTAR RUJUKAN}

Al-Muhdar, A. S., Indria, D.W., \& Rusnianah, F. (2018). Efektivitas Pemberian E-Booklet tentang Permasalahan Menyusui terhadap Peningkatan Pengetahuan Dokter Umum di Puskesmas Kota Malang. Jurnal Kesehatan Islam, 7(1), 1-10.

Akbar. S. (2016). Instrumen Perangkat Pembelajaran. Bandung: PT Remaja Rosdakarya.

Bolejko, A., Sarvik, C., Hagell, P., \& Brinck, A. (2008). Meeting Patient Information Needs Before Magnetic Resonance Imaging: Development and Evaluation of an Information Booklet. Journal of Radiology Nursing, 27(3), 96-102. https://doi.org/10.1016/j.jradnu.2008.05.001

Citrawathi, D. M., Adnyana, P. B., \& Maryam, S. (2009). Analisis Kebutuhan Dalam Pengembangan Buklet Edukatif Tematik (BET) Untuk Pendidikan Kesehatan Di SD. Jurnal Pendidikan dan Pengajaran, 42(2), 187-195.

Dinas Pertanian dan Ketahanan Pangan Provinsi Jawa Timur. (2015). Publikasi Sentra Holtikultura Kabupaten Banyuwangi. (Online). http://pertanian.jatimprov.go.id/index.php/komoditas/sentra-hortikultura/4-kab-banyuwangi, diakses 29 Mei 2017.

El-Sayd, A. A., \& El-Deep Soha, M. (2014). The Economic Evaluation of Extension Activities in Forage Crops Production in Sinai Peninsula, Egypt. Annals of Agricultural Sciences, 59(1), 83-88. https://doi.org/10.1016/j.aoas.2014.06.012

Eschalier, B., Descamps, S., Boisgard, S., Pereira, B., Lefevre-Colau, M.M., Claus, D., \& Coudeyre, E. (2013). Validation of an Education Booklet Targeted to Patients Candidate for Total Knee Arthroplasty. Orthopaedics and Traumatology: Surgery and Research, 99(3), 313-319. https://doi.org/10.1016/j.otsr.2013.01.007

Gombe, S. Y., Suandi, T. Bin, Arif, I., \& Zohara Omar, I. (2016). Extension Education's Role towards Community Empowerment in Nigeria: Issues, Challenges and Prospects. Journal of Education \& Social Policy, 3(2), $135-142$.

Guillot, C. \& Keenan, G. (2016). The Evaluation of an Information Booklet in The Use of Effective Patient Communication in The Setting of Thoracic Anesthesia. Patient Experience Journal, 3(2), 57-66.

Kaleka, N. (2015). Budidaya Melon. Surakarta: BISA! Publising.

Oliveira, S. C. de, Lopes, M. V. de O., \& Fernandes, A. F. C. (2014). Development and validation of an educational booklet for healthy eating during pregnancy. Revista Latino-Americana de Enfermagem, 22(4), 611-620. https://doi.org/10.1590/0104-1169.3313.2459

Pereira, S., Pinto, M., \& Pereira, L. (2012). Resources for Media Literacy: Mediating the Research on Children and Media. Scientific Journal of Media Education, 20(39), 91-99. https://doi.org/10.3916/c39-2012-02-09

Pribadi, B. A. (2017). Media dan Teknologi dalam Pembelajaran. Jakarta: PT. Balebat Dedikasi Prima.

Raco, J. R. (2013). Metode Penelitian Kualitatif Jenis Karakteristiknya dan Keunggulannya. Jakarta: Grasindo.

Republik Indonesia. (2006). Undang-undang Nomor 16 Tahun 2006 Tentang Sistem Penyuluhan Pertanian, Perikanan, dan Kehutanan (UU SP3K).

Republik Indonesia. (2003). Undang-undang Nomor 20 Tahun 2003 Tentang Sistem Pendidikan Nasional.

Sachriani., Ruslianti., \& Dahlia, M. (2019). The Effectiveness of Using Interactive CD Media on Continental Cake Processing to Improve Learning Outcomes of Course Participants in Culinary. KnE Social Sciences, 3(12), 126-137. https://doi.org/10.18502/kss.v3i12.4079

Sulaiman, M., Ngabekti, S., \& Widiatningrum, T. (2018). The Development of Booklet about the Variety of Macroscopic Fungi Species in Arboretum Sylva Western Borneo as the Supplement of Learning Material at High School. Journal of Innovative Science Education, 7(2), 343-351.

Sungkono. (2009). Pengembangan Bahan Ajar. Yogyakarta: Universitas Negeri Yogyakarta. 